\title{
Successful Use of Squeezed-Fat Grafts to Correct a Breast Affected by Poland Syndrome
}

\author{
Hyunjin Yang $\cdot$ Heeyoung Lee
}

Received: 28 February 2010/ Accepted: 19 August 2010/Published online: 17 October 2010

(C) The Author(s) 2010. This article is published with open access at Springerlink.com

\begin{abstract}
This study attempted to reconstruct deformities of a Poland syndrome patient using autologous fat tissues. All injected fat tissues were condensed by squeezing centrifugation. Operations were performed four times with intervals over 6 months. The total injection volume was $972 \mathrm{ml}$, and the maintained volume of $628 \mathrm{ml}$ was measured by means of a magnetic resonance image (MRI). The entire follow-up period was 4.5 years. After surgery, several small cysts and minimal calcifications were present but no significant complications. The cosmetic outcomes and volume maintenance rates were excellent despite the overlapped large-volume injections. In conclusion, higher condensation of fat tissues through squeezing centrifugation would help to achieve better results in volume maintenance and reduce complications. It is necessary, however, to perform more comparative studies with many clinical cases for a more scientific analysis. The study experiments with squeezed fat simply suggest a hypothesis that squeezing centrifugation could select healthier cells through pressure disruption of relatively thinner membranes of larger, more vulnerable and more mature fat cells.
\end{abstract}

Keywords Breast fat augmentation - Condensed fat - Fat gel $\cdot$ Poland syndrome $\cdot$ Squeezed fat

H. Yang $\cdot$ H. Lee $(\bowtie)$

Kangnam Plastic Surgery, 135-891, Gujung Building 3rd Floor,

Shinsa-Dong 577-7, Kangnam-Gu, Seoul, South Korea

e-mail: pslhy@medimail.co.kr
Poland syndrome is a birth defect with a variety of associated anomalies occurring around the upper limbs and torso. It may include ipsilateral deformities such as underdevelopment or absence of the main chest muscle (pectoralis major) and secondary muscles of the chest and axillary region; missing sternal head of the pectoralis muscle; underdevelopment or absence of the nipple, areola, and (in women) underlying breast tissues; hypoplastic skin and subcutaneous layers; missing portions of the ribs or costal cartilages; missing axillary hair; and short, webbed fingers (cutaneous syndactyly) and a shortened forearm [4]. The main concerns for women with Poland syndrome usually are aesthetic corrections of the breast rather than its functional restoration [4].

For this procedure, we used a large-volume injection of fat, which generally is not recommended for this type of procedure. The cosmetic result exceeded our expectations. A magnetic resonance image (MRI) showed an increase in the maintenance of fat graft volume after performance of a breast augmentation for the patient with Poland syndrome. The formation of cysts was minimal.

For several decades, many reports and articles have noted the significant problems associated with autologous fat injections into the breasts [5]. On the other hand, significant developments of the methods for autologous fat injections into the breasts have provided improved results [6].

Although the mechanism contributing to the increased graft survival rate in large-volume fat (or tissues) injection into the breast of the patient with Poland syndrome calls for further research, various possibilities are discussed. Assuming that the exact mechanism is found, this procedure would be a viable alternative for the treatment of congenital breast deformity and postmastectomy conditions in patients with breast cancer. 


\section{Materials and Methods}

\section{Materials}

We used an aseptic squeezing centrifugation lipotransfer (SCL) system (Lipokit; Medikan Co. Ltd., Seoul, Korea) that increases the density of adipose-derived stem cells (ASCs) and interstitial structures through the removal of older fat cells and liquid triglycerides. This procedure provides an all-in-one, closed-circuit process using a single-use, 50-ml syringe container with a weight-mesh-filtering piston plunger. During the entire procedure, fat always stays within the same single-use syringe. During the centrifugation, the weight-mesh-filtering piston squeezes the liposuction aspirates within the same syringe, disrupting the larger and older vulnerable fat cells and condensing the fat tissues while simultaneously removing liquid triglycerides and fluid impurities.

In the other preparations, this technique was not significantly different from the conventional syringe techniques. Tumescent fluid was made using 11 of Hartmann's solution with $2 \mathrm{ml}$ of epinephrine $(1 \mathrm{mg} / 1 \mathrm{ml})$. The tumescent fluid injection was made with compressed air using the same syringe.

Centrifugation was performed at 3,000 $\mathrm{g}$ for $5 \mathrm{~min}$ with the same syringes used in harvesting. Injection of processed fat also was performed with the same syringes using compressed air and a manual spiral plunger. During fat injection, we tried to disperse the fat evenly. We injected fat into the soft tissues so that we would not invade intercostal spaces.

We instructed the patient not to use the right arm vigorously for 2 weeks. We did not use a massage technique, which usually is applied with silicon implantation techniques. We injected first-generation cephalosporin as a prophylactic antibiotic $1 \mathrm{~h}$ before a surgery. Oral antibiotics were used for 5 days after the operations.

\section{Patients and Methods}

A 23-year-old woman showed several signs of Poland syndrome on her right side including absence of the right breast, defects of chest muscles such as the pectoralis major, defects in the ribs and costal cartilages, and webbing of the axillary fold, hypoplastic skin, and subcutaneous tissues. The patient's rib cage also was unusually small. Her height was $160 \mathrm{~cm}$, and her body weight was $57 \mathrm{~kg}$. The latter gradually increased by $6 \mathrm{~kg}$ and was at $63 \mathrm{~kg}$ at the final surgery.

The patient did feel some discomfort, but her contralateral side, including the breast, was well developed. She underwent several plastic surgery consultations that offered the possibility of free flaps but required the sacrifice of other body parts for breast reconstruction. Flap surgery was not an option because the patient did not want any type of "bodily sacrifice" or scarring. Therefore, we at first recommended using a skin expander and a silicon implant. The patient also refused this option due to the size limitation of the implant and the possible asymmetry of the depressed chest wall. Finally, we recommended serial fat injections.

We performed the first surgery on 12 February 2005. During the surgery, we injected $220 \mathrm{ml}$ of autologous fat into the right breast. The second surgery was performed nearly 1 year later, on 3 January 2006. For the second surgery, we injected $212 \mathrm{ml}$ of fat.

We performed mammography at 6-month intervals. A breast MRI was performed on 24 July 2006. Abnormalities such as masses, cysts, and calcifications were not present at the final mammography. As a result, we decided to perform a third operation. We recommended using a cohesive gel implant, but the patient also refused this option due to possible complications arising from a foreign material inside her body. As a result, we performed the third surgery on 5 January 2007, injecting $295 \mathrm{ml}$ of fat.

\section{Results}

We performed a breast MRI 6 months after the third surgery on 5 January 2007, approximately 2 years after the first fat injection. The MRI indicated no significant problems, including no instance of capsule formation. We planned to perform the final fat injection of $240 \mathrm{ml}$ on 3 March 2008. We then performed the final mammography, sonography, and size-calculable MRI with a dye contrast. We found several small benign cysts. Based on our 269 cases dealing with fat injections into the breast, we considered these small cysts to be a minimal problem. The cysts could be treated easily by sono-guided needle aspiration. However, the remaining capsule still carried the possibility of microcalcification development, which in turn could have caused confusion in the diagnosis by radiologists.

There was no lump or hardness after surgery, and the patient's satisfaction was very high. Serial photos showed little interval change and good skin expansion (Fig. 1). All radiologic findings showed only small cysts and no other abnormal findings (Figs. 2, 3, 4, 5). The MRI digital volume calculation showed $627 \mathrm{ml}$ of volume in the right breast (Fig. 6).

\section{Discussion}

The transfer of autologous fat dates back to the 1890s. In 1890, fat transplantation to body parts other than the 

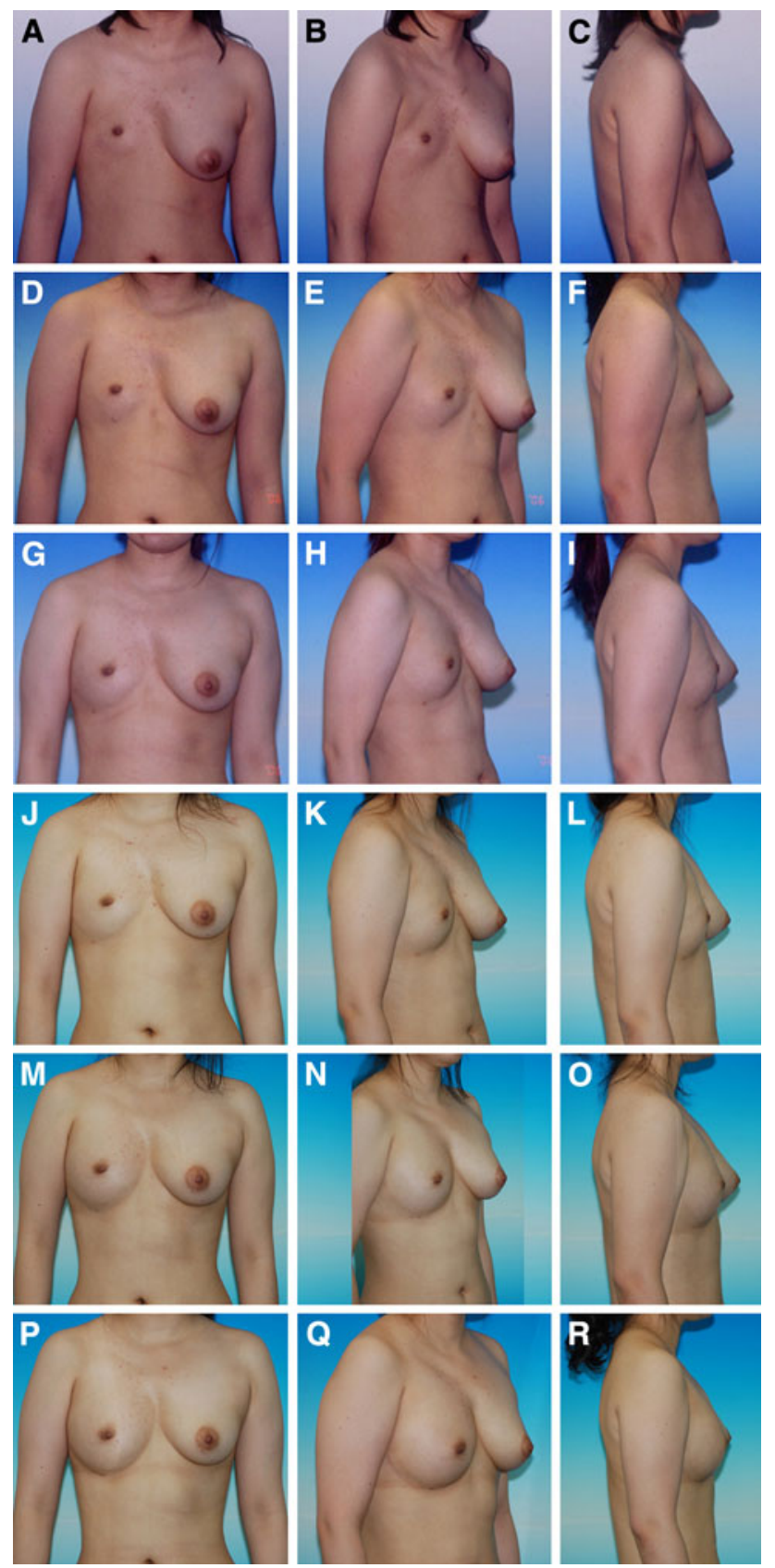

Fig. 1 Serial photos showing minimal interval change between 6 months and 1 year after the second surgery. a-c View 1 February 2005 before surgery. d-f View 3 January 20061 year after the first surgery. g-i View 24 July 20066 months after the second surgery. j-l View 26 January 20071 year after the second surgery. m-o View 9 January 20081 year after the third surgery. p-r View 24 May 2008 4 months after the fourth surgery

breasts was performed by Neuber. In 1992, Lexer transferred fat from the buttocks to the breast [1]. Since then, various fat-grafting procedures have been performed, providing positive results. However, the cosmetic results of breast fat-grafting procedures have been largely inconsistent, causing some side effects and leading to no shortage of disapproving responses to the procedure. Carpaneda and Ribeiro [2] found that only a minimal fraction of fat mass survives after the procedure.

Recently, Zocchi and Zuliani [3] proposed that microcalcification, which may cause false-positives in breast cancer screening, appears commonly with other forms of breast surgery and can be distinguished easily from the neoplastic surgeries. Microcalcification also appears in women with benign tumors who have undergone surgery. Thus, the appearance of microcalcification alone should not be a factor prohibiting the procedure.

High-tech diagnostic equipment has helped us measure exact volumes with ease. Of the $972 \mathrm{ml}$ of fat injected into the patient, $500 \mathrm{ml}$ formed living tissue. Although each of four fat injection sessions appeared to be problematic at first, they resulted in stable conditions after 6 months. It is not easy to explain exactly why this large volume of injected fat survived, but we can assume that this result cannot be attributed simply to the survival of grafted fat. A plausible theory dealing with the recently introduced ASCs may explain the result. Two studies have proposed that the presence of ASCs has clinical implications for autologous fat transfers because ASCs may contribute to neoangiogenesis in the acute phase by acting as endothelial progenitor cells (Miranville et al. [4]) or as angiogenicfactor-releasing cells (Rehman et al. [7]). It also could be theorized that the injected fat triggers stem cell differentiation within the affected area.

The aseptic SCL mechanism that we used could condense the healthy fat cells, ASCs, the patient's own peptides (growth factors), and scaffolds (extracellular matrix). It also may reduce complications from the destroyed old fat cells and the removed fluid triglycerides.

Yoshimura et al. [8] proposed that the short-term survival rate for aspirated adipose grafts per volumetric unit after centrifugation increased with centrifugal forces up to $3,000 \mathrm{~g}$. Condensation of the graft material and ASCs is thought to contribute dominantly to this enhancement.

In addition, conditions of the soft tissues at the recipient site also are very important. If the recipient site is judged to be too small, serial expansions or preexpansion can help to increase recipient capacity, as recommended by Del Vecchio [9].

In our in vivo nude mice study, we also found significantly greater volume and weight with grafted fat produced by SCL than with simple centrifuged fat or liposuction fat. Generally, the older fat cells are relatively larger than the younger fat cells. As indirect evidence of our hypothesis, the smaller cell size in most of the squeezed fat implies that squeezing enables selective destruction of larger and older cells that tend to be more fragile. It is hypothesized as a physical phenomenon that if the thickness of cell membranes and pressures are equal, cells with larger volumes 
A

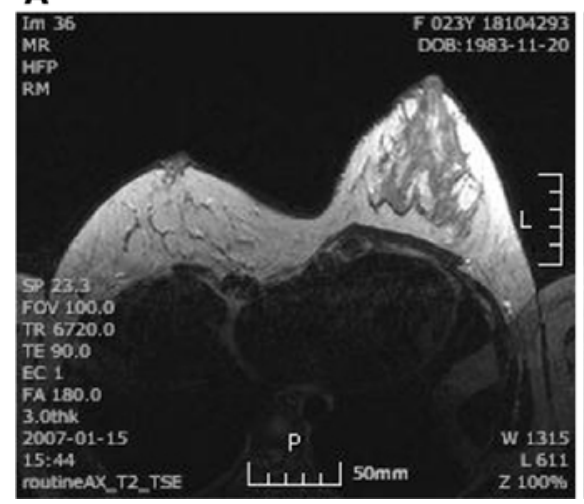

B

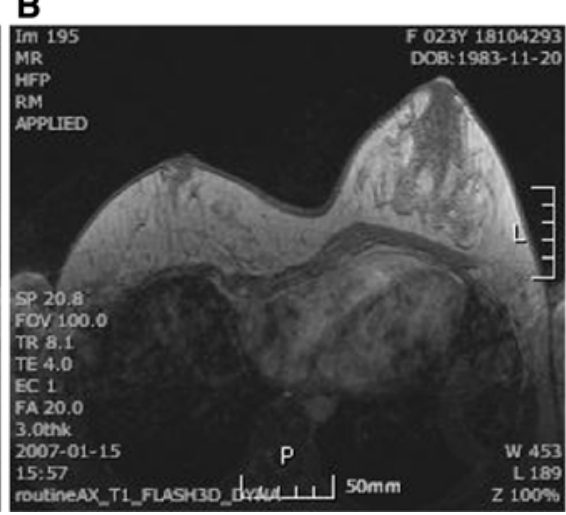

C

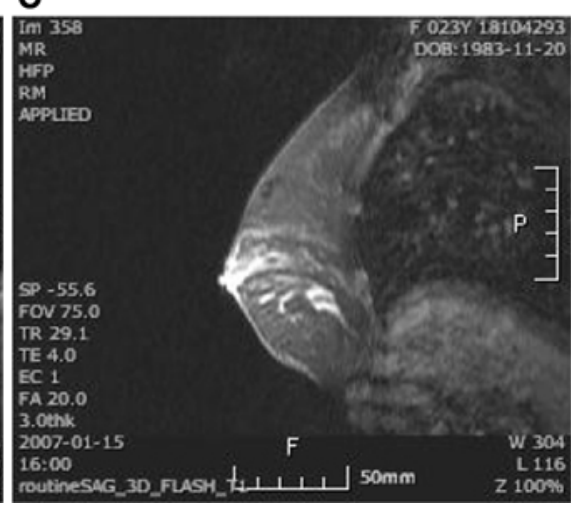

Fig. 2 Magnetic resonance image (MRI) 1 year after second surgery. a T2 axial view. b T1 axial view. c T1 sagittal view. Several cysts are smaller than $1 \mathrm{~cm}$, with no other pathologic findings
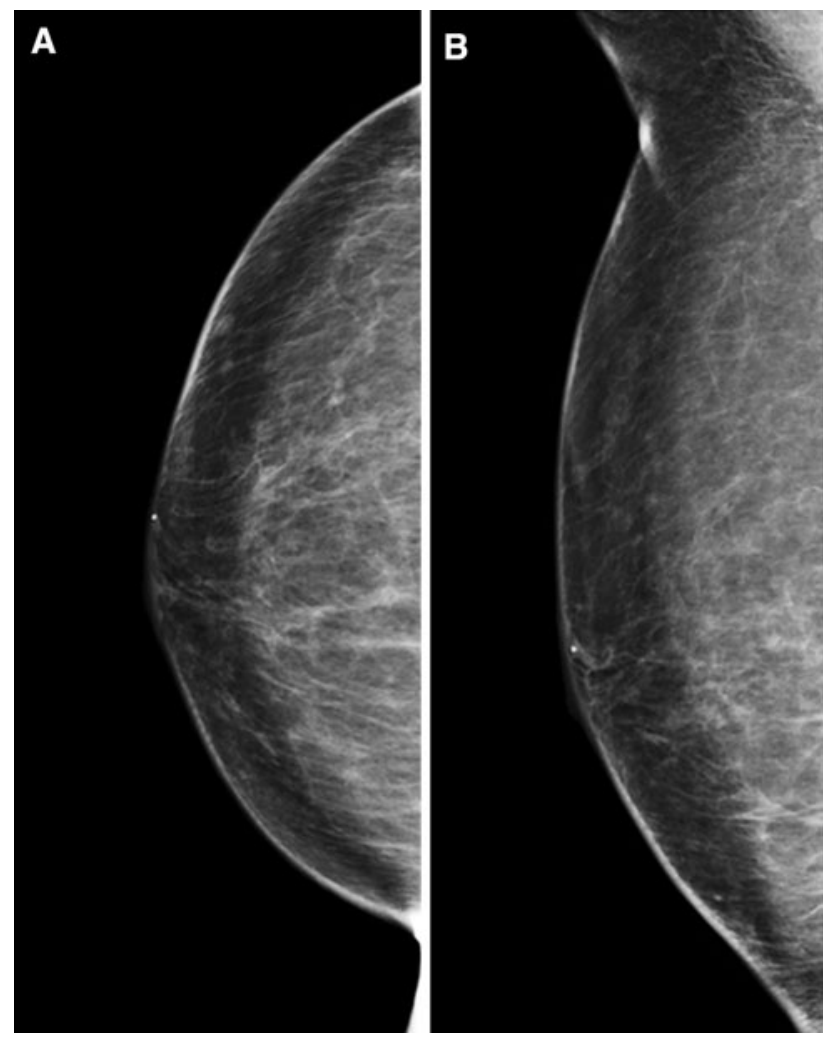

Fig. 3 Mammography $3 \frac{1 / 2}{2}$ years after the first surgery (4 months after the fourth surgery). a CC view. b MLO view. No significant calcification is seen

should endure mechanical stress, such as squeezing pressure, with a relatively smaller surface area than cells with smaller volumes. We regarded this squeezing process as a kind of preliminary pressure stage because all injecting fat must pass through high-pressure environments during injection in syringes, needles, and recipient tissues.

We used a 22-g piston plunger $2.6 \mathrm{~cm}$ in diameter and centrifuged at 3,000 $\mathrm{g}$ for $5 \mathrm{~min}$. We were able to calculate the pressure within fat tissues during centrifugation by assessing the actual weight $(0.022 \mathrm{~kg} \times 3,000)$ and cut surface area $(3.14 \times 1.3 \times 1.3 \mathrm{~cm})$. The pressure within the fat tissue was $12.5 \mathrm{~kg} / \mathrm{cm}^{2}$. We also tried to evaluate the harmful influences of this squeezing process by comparing the viabilities of $1 \mathrm{ml}$ of crude fat and $1 \mathrm{ml}$ of squeezed fat. The total number of ASCs increased in unit volume, but the viability comparison did not show significant differences (Fig. 7a-c). This finding implies that actual condensation occurred and that the squeezing process did not have significant harmful effects on ASC.

In our other experimental trials, we injected squeezed fat, normal fat, and simple centrifuged fat into nude mice $(n=10)$ and killed the mice at 8 weeks. We compared the volume, weight, and histologic findings of each fat graft. The average size of a fat cell in each sample was compared in microscopic fields. We counted the number of pixels within each cell membrane and compared the average number of pixels of fat cell size before injection.

As a result, the survival rate for injected squeezed fat was significantly higher than for the fats of other groups (Fig. 8a-c). The average cell size in the squeezed fat was significantly smaller than in the centrifuged fat (Fig. 9a-c). It may be thought that the findings emerged by coincidence, but it is important to note the involvement of scaffolds and cell signals in the growth of undifferentiated stem cells and body tissues. Therefore, we suggest that the more destructed forms of fat tissues can be regarded as the more exaggerated experimental models of destructed fat. Gross tissue destruction usually indicates a reduction in tissue viability, but our destruction method of squeezing fat did not reduce tissue viability.

Fat tissues are composed not only of adipocytes but also of stem cells, scaffolds, and growth signals such as growth factors. We therefore have hypothesized that targets of condensation may not be adipocytes. In small-volume fat grafts, we often use gel-like fat tissues made by the 
Fig. 4 Magnetic resonance image (MRI) $3 \frac{1}{2}$ years after the first surgery (4 months after the fourth surgery). a T1 axial view. b CET1 axial delay view. c MIP axial view. d T1 sagittal view. Several cysts are smaller than $1 \mathrm{~cm}$, with no other pathologic finding
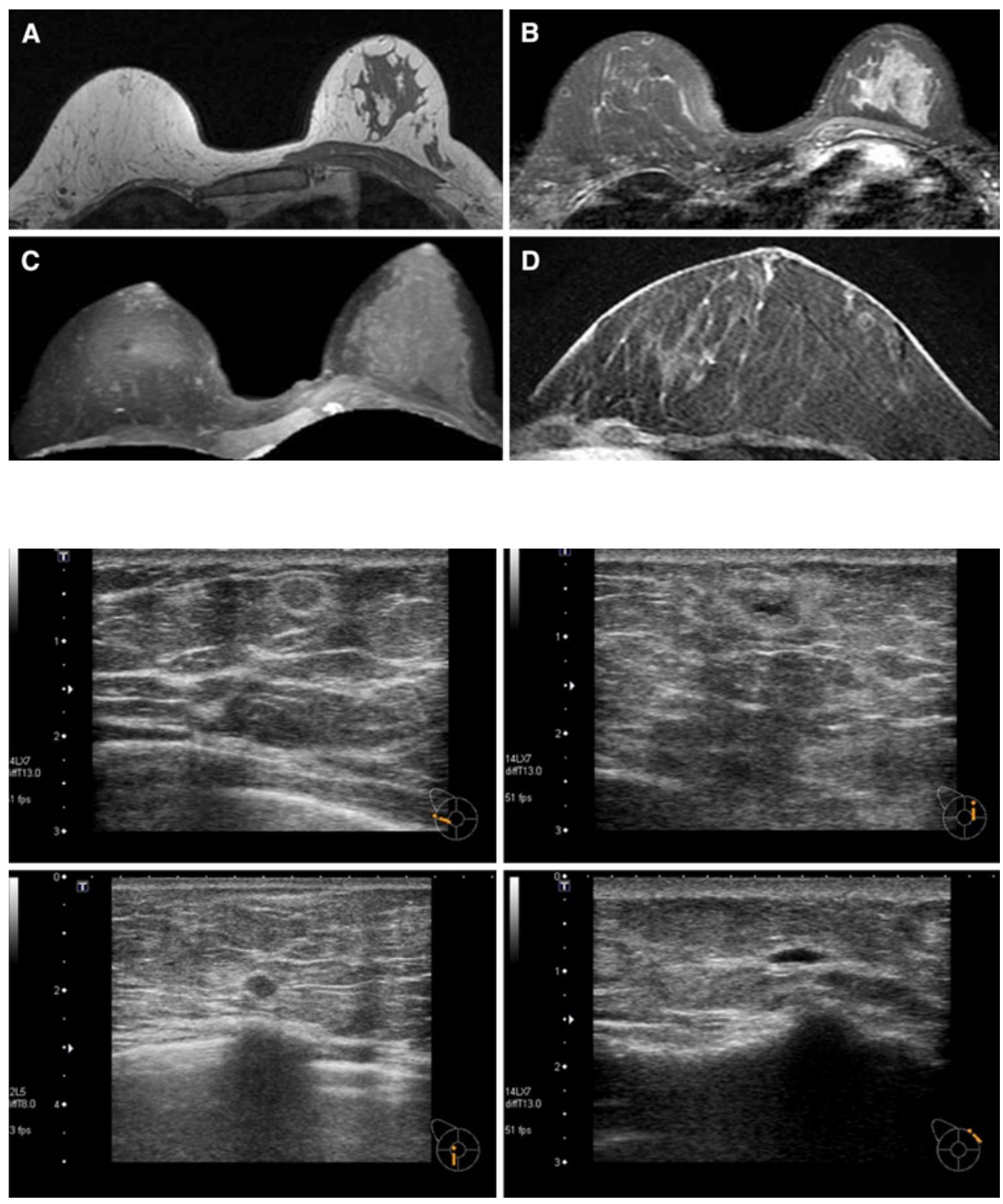

Fig. 5 Sonography $3 \frac{1}{2}$ after the first surgery (4 months after the fourth surgery). Small fluidfilled cysts are seen sharp-blade homogenization process. We call this gel-like tissue, composed of micronized condensed fat tissues, "fat gel." Highly condensed viable stem cells and collagen structures are abundant in these tissues. This finding supports our rationale that mechanical destruction may positively affect fat grafting (Fig. 10). We almost always use this type of condensed fat tissue for fine-finishing fat grafting to correct an incidental irregularity or areola defining because fat gel can be injected with thinner needles (e.g., 26 gauge). We can suggest this process as another type of mechanical destructing condensation, but this procedure also requires long-term follow-up assessment and discussion.

The significance of our procedure goes beyond deformity restoration. Both analysis of genes and noninvasive tracing on animals will clarify this point further. High-tech equipment in experiments is needed to pinpoint the exact cause.
We believe the result of our procedure will cause considerable discussion regarding its meaning and implication.

Conversely, with the increase in soft tissue, the shrunken cavity of the anterior chest appeared to be straighter in a resting position. We made this conjecture according to the direction of the nipples.

\section{Conclusions}

The reported case has the largest breast created to date by fat injection only, supported by official records and diagnostic means. Currently, we do not know the possibility of success because we conducted only four procedures of repeated massive fat transfers to the same area, using more than $200 \mathrm{ml}$ per procedure to combat Poland syndrome. 
Fig. 6 Magnetic resonance image (MRI) volume calculation $3 \frac{1}{2}$ years after the first surgery (4 months after the fourth surgery). a-c Left breast, normal side with no operation $\left(412.876 \mathrm{~cm}^{3}\right)$. d-f Right breast, affected side with four operations $\left(627.701 \mathrm{~cm}^{3}\right)$
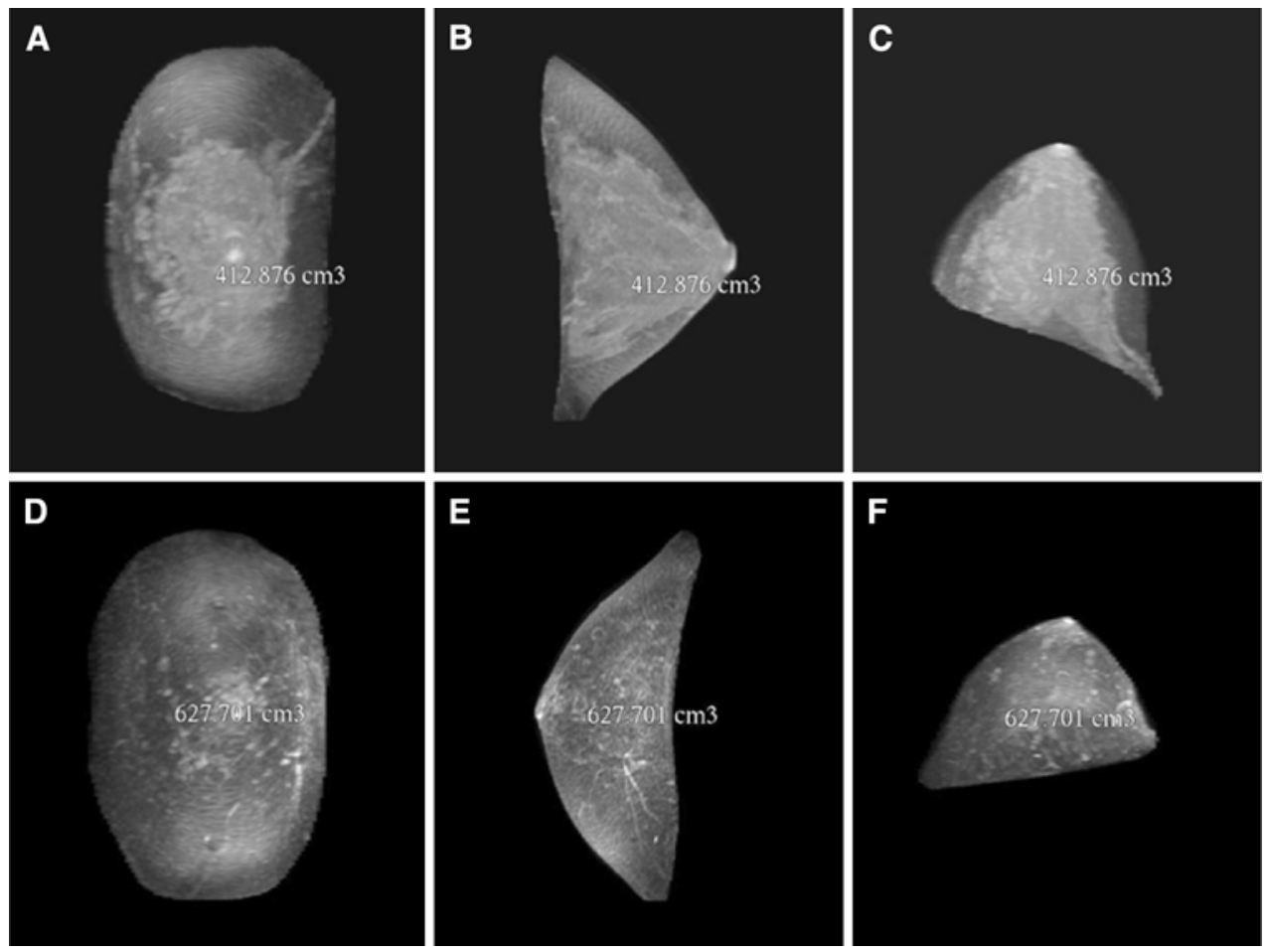

A

\begin{tabular}{|c|c|c|c|c|c|c|c|c|}
\hline & \multicolumn{4}{|c|}{ Simple centrifuged fat } & \multicolumn{5}{c|}{ Squeezed fat } \\
\cline { 2 - 10 } & $\begin{array}{c}\text { Total cell } \\
\left(\times 10^{5}\right)\end{array}$ & $\begin{array}{c}\text { Dead cell } \\
\left(\times 10^{5}\right)\end{array}$ & $\begin{array}{c}\text { Viable cell } \\
\left(\times 10^{5}\right)\end{array}$ & Viability \% & $\begin{array}{c}\text { Total cell } \\
\left(\times 10^{5}\right)\end{array}$ & $\begin{array}{c}\text { Dead cell } \\
\left(\times 10^{5}\right)\end{array}$ & $\begin{array}{c}\text { Viable cell } \\
\left(\times 10^{5}\right)\end{array}$ & Viability \% \\
\hline Female (25) & 4.01 & 0.28 & 3.73 & 93.02 & 9.91 & 0.68 & 9.23 & 93.14 \\
\hline Male (29) & 5.82 & 0.68 & 5.14 & 88.31 & 12.00 & 0.19 & 10.10 & 84.17 \\
\hline Female (46) & 4.93 & 0.52 & 4.41 & 89.45 & 6.00 & 0.52 & 5.48 & 91.33 \\
\hline Female (27) & 4.39 & 0.98 & 3.40 & 84.35 & 4.91 & 0.35 & 4.56 & 87.97 \\
\hline $\begin{array}{c}\text { Average } \\
\text { (Std. err.) }\end{array}$ & $\begin{array}{c}4.79 \\
(0.39)\end{array}$ & $\begin{array}{c}0.62 \\
(0.15)\end{array}$ & $\begin{array}{c}4.17 \\
(0.36)\end{array}$ & $\begin{array}{c}88.78 \\
(1.79)\end{array}$ & $\begin{array}{c}8.21 \\
(1.66)\end{array}$ & $\begin{array}{c}0.44 \\
(0.11)\end{array}$ & $\begin{array}{c}7.34 \\
(1.37)\end{array}$ & 89.15 \\
\hline
\end{tabular}

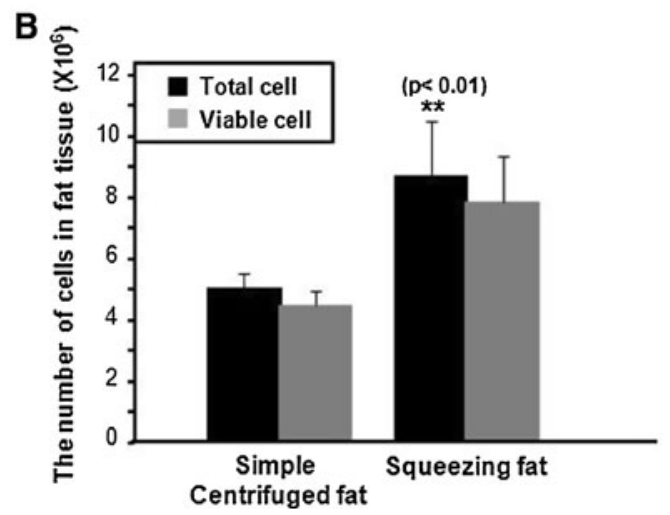

Fig. 7 Cell counts and viabilities in simple centrifuged fat and squeezed fat. a Numbers of viable cells in simple centrifuged fat and squeezed fat, respectively. b Numbers of cells in simple centrifuged

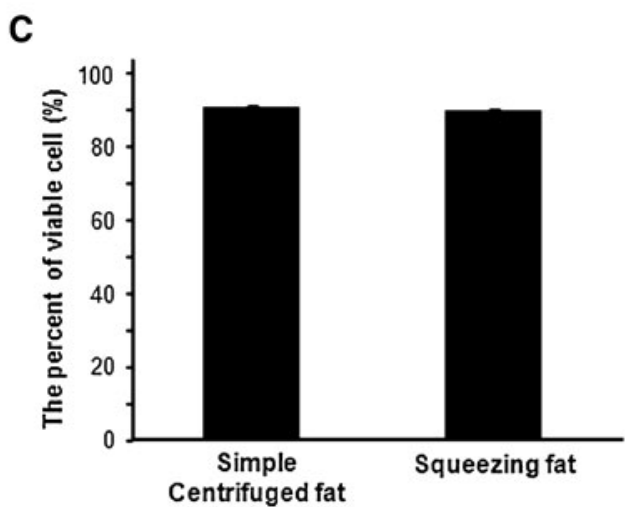

fat and squeezed fat, respectively. c Cell viability in simple centrifuged fat and squeezed fat, respectively 
A
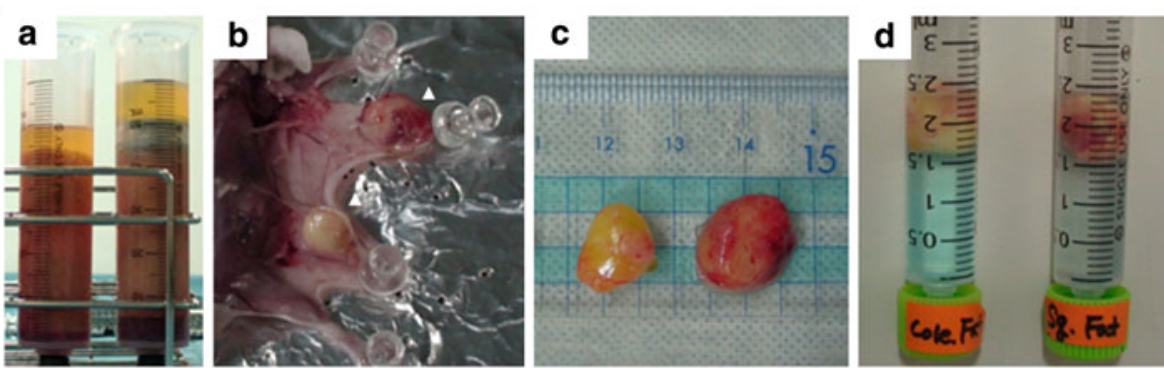

B

\begin{tabular}{|c|c|c|c|c|}
\hline $\begin{array}{c}\text { remained fat } \\
\text { volume }\end{array}$ & $\begin{array}{c}\text { Simple } \\
\text { centrifuged fat } \\
\text { 4week }\end{array}$ & $\begin{array}{c}\text { Simple } \\
\text { centrifuged fat } \\
\text { 8week }\end{array}$ & $\begin{array}{c}\text { Squeezed fat } \\
\text { 4week }\end{array}$ & $\begin{array}{c}\text { Squeezed fat } \\
\text { 8week }\end{array}$ \\
\hline average & 0.286 & 0.243 & 0.362 & 0.294 \\
\hline std.err. & 0.0212 & 0.0338 & 0.0563 & 0.0245 \\
\hline size & 10 & 10 & 10 & 10 \\
\hline
\end{tabular}

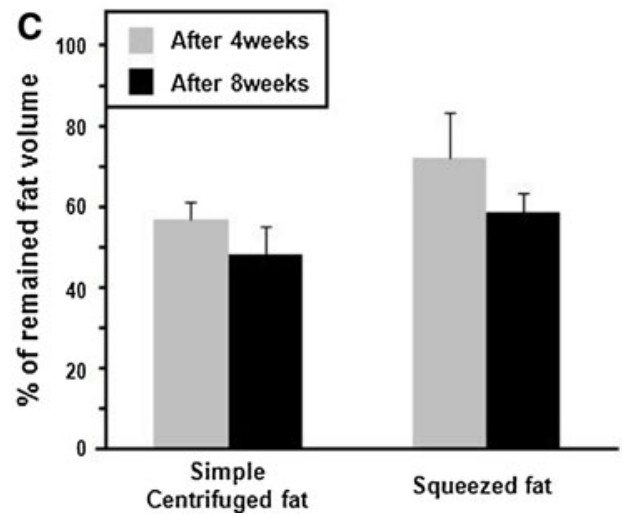

Fig. 8 Morphologic analysis comparing simple centrifuged fat and squeezed fat. A $(a, c, d)$ Left: Simple centrifuged fat. Right: Squeezed fat. $b$ Upper: Squeezed fat. Lower: Simple centrifuged fat. B Comparative analysis of the remaining fat volumes of simple centrifuged fat versus squeezed fat. C Graph showing the percentage of the remaining fat volume after 4 and 8 weeks in simple centrifuged fat and squeezed fat, respectively
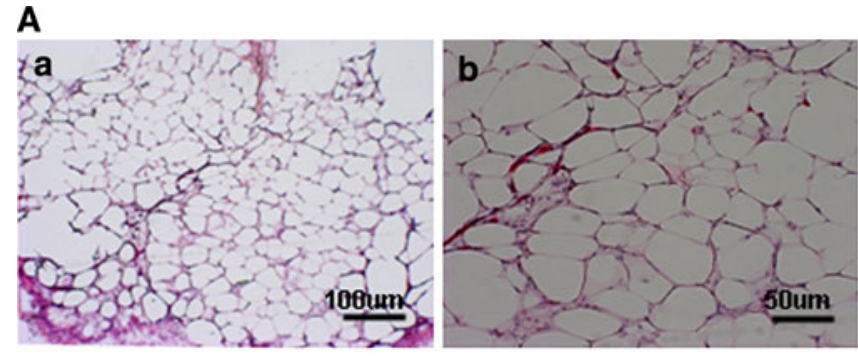

B

\begin{tabular}{|c|c|c|}
\hline pixel number & $\begin{array}{c}\text { Simple } \\
\text { centrifuged fat }\end{array}$ & Squeezed fat \\
\hline Count & 30 & 30 \\
\hline Average & $7.47 \times 10^{4}$ & $6.10 \times 10^{4}$ \\
\hline Standard Error & $0.61 \times 10^{4}$ & $0.47 \times 10^{4}$ \\
\hline
\end{tabular}
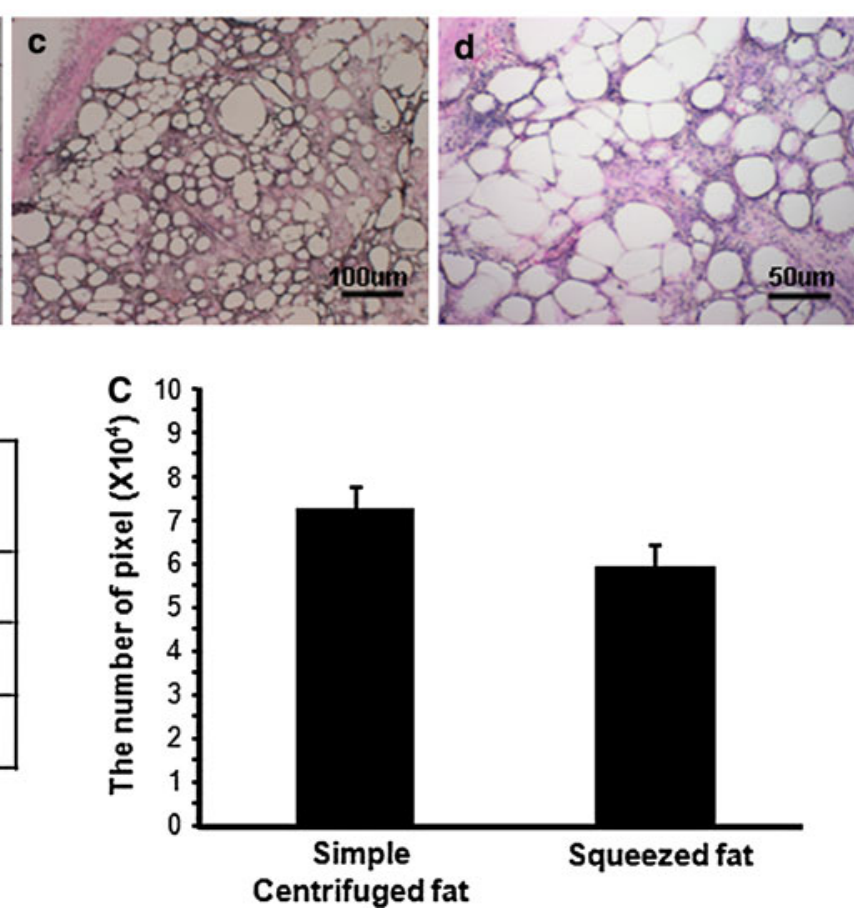

pixels used by the Adobe Photoshop CS2 program. To assess the size of the Coleman fat and the squeezed fat quantitatively, we randomly selected 30 single fat cells from five fat photos $(\times 100)$ in each group and then measured the pixel numbers of each fat image used for the polygonal Lasso Tool in the Adobe Photoshop CS2 program 

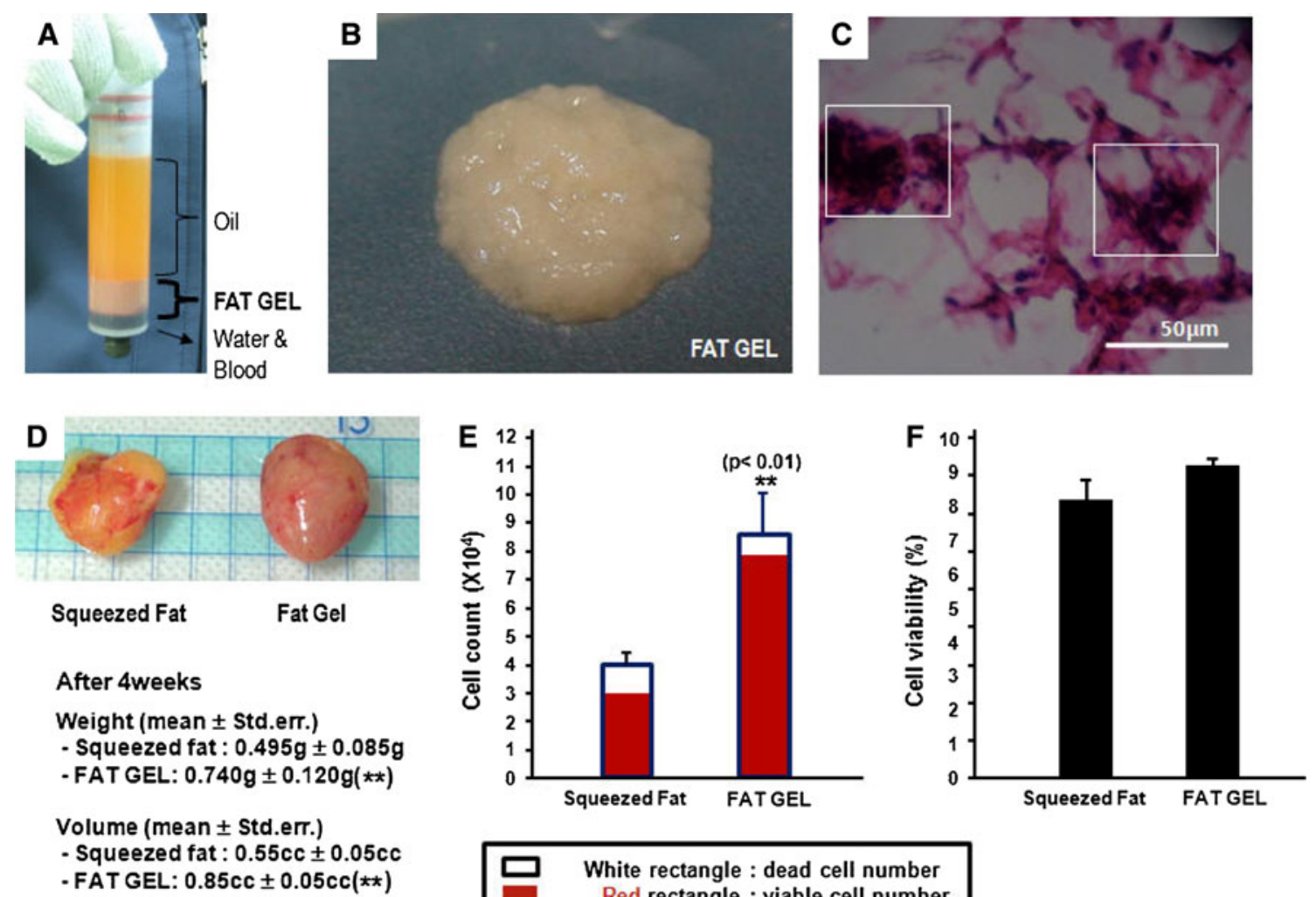

- SAT GEL: $0.85 \mathrm{cc} \pm 0.05 \mathrm{cc}(\star \star)$

White rectangle : dead cell number

Red rectangle : viable cell number Blue line rectangle : total cell number

Fig. 10 Highly condensed fat tissues ("fat gel") using sharp-blade medical homogenizer. a Morphology of fat gel made by the medical homogenizer (Filler-Geller; Medikan Co. Ltd., Seoul, Korea). b Gross morphology of fat gel. c Histologic analysis of fat gel. Hematoxylin and eosin (H\&E) staining of fresh fat gel. Violet (nucleus). Pink

For additional analysis of this mechanism, more investigations and cases are needed.

In conclusion, a higher condensation of fat tissues through squeezing centrifugation would improve results, increase volume maintenance, and reduce complications. Again, however, it is necessary to perform further comparative studies using several clinical cases to achieve a more scientific analysis.

Conflict of interest The author has no conflict of interest to declare with regard to this article.

Open Access This article is distributed under the terms of the Creative Commons Attribution Noncommercial License which permits any noncommercial use, distribution, and reproduction in any medium, provided the original author(s) and source are credited. (cytoplasm). White rectangle (location at which the stem cell is highly condensed). d Comparison of volume maintenance between squeezed fat and fat gel in nude mice after 4 weeks. e Cell-counting analysis comparing squeezed fat and fat gel. $\mathbf{f}$ Comparison of adipose-derived stem cell (ASC) viability between squeezed fat and fat gel

2. Carpaneda CA, Ribeiro MT (1993) Study of the histological alterations and viability of the adipose graft in humans. Aesthetic Plast Surg 17:43-47

3. Zocchi ML, Zuliani F (2008) Bicompartmental breast lipostructuring. Aesthetic Plast Surg 32:313-328

4. Miranville A, Heeschen C, Sengenes C et al (2004) Improvement of postnatal neovascularization by human adipose tissue-derived stem cells. Circulation 110:349

5. Pohl P, Uebel O (1985) Complications with homologous fat grafts in breast augmentation surgery. Aesthetic Plast Surg 9:87-89

6. Coleman S, Saboeiro A (2007) Fat grafting to the breast revisited: safety and efficacy. Plast Reconstr Surg 119:775-785

7. Rehman J, Traktuev D, Li J et al (2004) Secretion of angiogenic and antiapoptotic factors by human adipose stromal cells. Circulation 109:1292

8. Yoshimura K, Harii K et al (2008) Influences of centrifugation on cells and tissues in liposuction aspirates: optimized centrifugation for lipotransfer and cell isolation. Plast Reconstr Surg 121:1033

9. Del Vecchio D (2009) Breast reconstruction for breast asymmetry using recipient-site preexpansion and autologous fat grafting: a case report. Ann Plast Surg 62:523-527

\section{References}

1. Hinderer UT, Del Rio JL (1992) Erich Lexer's mammaplasty. Aesthetic Plast Surg 16:101-107 